\title{
Effect of sterilized human fecal extract on the sensitivity of Escherichia coli ATCC 25922 to enrofloxacin
}

\author{
Youngbeom Ahn, Kidon Sung, Fatemeh Rafii and Carl E Cerniglia
}

The ingestion of antimicrobial residues in foods of animal origin has the potential risk of exposing colonic bacteria to small concentrations of antibiotics and inducing resistance in the colonic bacteria. To investigate whether human intestinal contents would influence resistance development in bacteria, Escherichia coli ATCC 25922 (MIC of enrofloxacin $<0.03 \mu \mathrm{gl}^{-1}$ ) was exposed to 0.01 to $1 \mu \mathrm{g} \mathrm{ml}^{-1}$ of enrofloxacin in media supplemented with glucose, sucrose, sodium acetate or sterilized human fecal extract. In the first passage, only the medium containing sterilized fecal extract supported the growth of $E$. coli at an enrofloxacin concentration equal to the MIC. In the second and third passages following exposure to sub-inhibitory concentrations of the drug, the bacteria in media containing sterilized fecal extract grew at $0.1 \mu \mathrm{g} \mathrm{ml}^{-1}$ of enrofloxacin. The efflux pump inhibitors, reserpine and carbonyl cyanide-m-chlorophenylhydrazone (CCCP), increased the sensitivity of bacteria to $0.1 \mu \mathrm{g} \mathrm{ml}^{-1}$ of enrofloxacin in the medium containing sucrose, but their effect was not observed in the medium supplemented with $2.5 \%$ sterilized fecal extract. The proportions of unsaturated and saturated fatty acids in $E$. coli grown in the medium with $2.5 \%$ sterilized fecal extract differed from those grown in the medium alone. Fecal extract may contain unknown factors that augment the ability of $E$. coli to grow in concentrations of enrofloxacin higher than MIC, both in the presence and absence of efflux pump inhibitors. This is the first study showing that fecal extract affects the level of sensitivity of $E$. coli to antimicrobial agents.

The Journal of Antibiotics (2012) 65, 179-184; doi:10.1038/ja.2012.1; published online 25 January 2012

Keywords: enrofloxacin; E. coli; fluoroquinolone; sterilized human fecal extract

\section{INTRODUCTION}

The use of antimicrobial agents in food-producing animals may result in the presence of low concentrations of drugs or their metabolites in food. ${ }^{1-5}$ The issue of whether residues of antimicrobial agents ingested in foods pose a danger to human health by increasing the population of bacteria that are insensitive to these substances has not been fully examined. ${ }^{6,7}$ Continuous exposure of the human colonic microbiota to antimicrobial agents from treated food animals may lead to elimination of highly sensitive commensal strains, allowing infection by opportunistic pathogens, or to exertion of selective pressure on the intestinal microbiota, favoring the growth of microorganisms less sensitive to the drugs and resistance development in bacteria that were previously sensitive. ${ }^{1,2,7-10}$

Enrofloxacin is a fluoroquinolone antimicrobial agent effective against a broad spectrum of Gram-positive and Gram-negative bacteria. ${ }^{11,12}$ It is used in veterinary medicine for the treatment of a variety of infections, including those in food-producing animals. Fluroquinolone-resistant strains of various colonic bacteria including Escherichia coli, may develop following exposure to these drugs.
Two main reasons for the fluoroquinolone-resistance are mutations in the drug targets gyrase A and topoisomerase IV, and extrusion of the drug via an efflux pump. Mutations at the quinolone resistancedetermining region (QRDR) of target genes may alter the binding of quinolones to this region and lead to reduced sensitivity or resistance to quinolones. ${ }^{13}$ The gyrA mutations and over-expression of efflux pump gene appear to be prevalent in clinical isolates of various bacteria including E. coli. ${ }^{14-20}$

Fecal slurries are a complex mixture of digested and undigested food, viable and non-viable bacteria, bacterial fermentation products and metabolites, and human cells and secretions. ${ }^{21}$ The inactivation of antibiotics by fecal materials has been shown in vitro. ${ }^{22-24}$ Drug inactivation can be due either to binding to insoluble components of fecal slurries, ${ }^{25}$ or to enzymatic modification. ${ }^{26}$ Unknown chemical properties of feces can affect binding or inactivation of antibiotic residues. ${ }^{27}$ However, there are no studies investigating the effect of human fecal extracts on the sensitivity of E. coli to the veterinary antimicrobial enrofloxacin or on the ability of bacteria to develop resistance to this drug. 
Ingestion of residues of antimicrobial agents in foods from treated animals may have the potential to influence the antimicrobial sensitivity of the members of the colonic microbial community. In this study, we have measured the effect of a low concentration of enrofloxacin on the sensitivity of an E. coli strain grown in media with and without sterilized fecal extract.

\section{MATERIALS AND METHODS}

\section{Bacterial strain and growth media}

E. coli ATCC 25922, for which the MIC of enrofloxacin is reported to be $0.03 \mu \mathrm{g} \mathrm{ml}^{-1}, 28$ was grown in $10 \mathrm{ml}$ of Mueller-Hinton broth (MHB, LabM, Farmingdale, NY, USA), at $37^{\circ} \mathrm{C}$ with shaking at 200 r.p.m. Autoclaved MHB was supplemented with filter-sterilized solutions of glucose, sucrose or sodium acetate to a final concentration of $5 \mathrm{~mm}$ or with 1 and $2.5 \%$ of human fecal extract.

\section{Preparation of sterilized fecal extract}

Fresh feces collected from three healthy individual volunteers, who had not been treated with any antibiotic for 6 months, were added to equal amounts $(w / v)$ of MHB. The use of human fecal samples was approved by the FDA Research Involving Human Subjects Committee (approval number 09-033T). The samples were mixed extensively to produce homogeneous suspensions. The fecal suspensions were further diluted with MHB to produce 10 and $25 \%$ $(\mathrm{w} / \mathrm{v})$ dilutions and sterilized by autoclaving at $121^{\circ} \mathrm{C}$ for $30 \mathrm{~min}$. The sterile fecal suspensions were centrifuged at $10000 \times \mathrm{g}$ for $10 \mathrm{~min}$ and filtered $(0.2 \mu \mathrm{m}$, $25 \mathrm{~mm}$, Millipore, Billerica, MA, USA). The extracts were transferred to new tubes for use in experiments. As the concentrated fecal extract is opaque and its OD is higher than the limit of detection by spectrophotometer, it was diluted in $\mathrm{MBH}$ medium to final concentration of 1.0 or $2.5 \%$, suitable for monitoring its effect on the growth of bacteria.

\section{Verification of the MIC of enrofloxacin}

The MIC of enrofloxacin for E. coli ATCC 25922 was verified in a 96-well microtiter plate. Serial dilutions of enrofloxacin, in concentrations ranging from 0.01 to $1 \mu \mathrm{g} \mathrm{ml}^{-1}$, were prepared in $200 \mu \mathrm{l}$ of MHB medium. The wells were inoculated with $2 \times 10^{5} \mathrm{CFU} \mathrm{ml}^{-1}$ and the plates were incubated for $24 \mathrm{~h}$ at $37^{\circ} \mathrm{C}$. The MIC of enrofloxacin, in which no bacterial growth was observed, was then determined.

\section{Kinetics of bacterial growth with enrofloxacin in supplemented MHB}

The effects of enrofloxacin on the kinetics of growth of E. coli ATCC 25922 in $\mathrm{MHB}$, in the presence and absence of $5 \mathrm{~mm}$ glucose, sucrose or acetate, or of 1.0 or $2.5 \%$ sterilized fecal extract, were measured as follows: $200 \mu \mathrm{l}$ of each of the media containing different additives was added to duplicate wells of 96-well plates. Dilutions of $0.01,0.02,0.03,0.06,0.1$ and $1 \mu \mathrm{g} \mathrm{ml}^{-1}$ of enrofloxacin were made in each of the media containing different additives. E. coli cells $\left(2 \times 10^{5} \mathrm{CFU} \mathrm{ml}{ }^{-1}\right)$ were added to each of the wells. Duplicate control wells, containing media without antibiotics and with and without additives, were also inoculated with the same number of cells. The microtiter plates were directly incubated in a Synergy MX spectrophotometer (BioTek Instruments, Winooski, VT, USA).

The kinetics absorbance assay protocol of the Gen5 microplate data collection and analysis software (BioTek Instruments) were used to measure and record the $\mathrm{OD}_{600}$ of the cells every $30 \mathrm{~min}$ for $15 \mathrm{~h}$ with shaking for various intervals. The kinetics of growth of E. coli grown with each of the concentrations of enrofloxacin in the medium with each of the additives was determined, subtracting the $\mathrm{OD}_{600}$ value of the non-inoculated medium with each of the additives. These experiments were repeated for three passages. E. coli grown in MHB was used for inoculation of plates in the first passage. Cells that had survived in MHB containing $0.01 \mu \mathrm{g} \mathrm{ml}^{-1}$ of enrofloxacin with different supplements were used for inoculation of each of the wells in the second passage. For the third passage, bacteria grown with $0.01 \mu \mathrm{g} \mathrm{ml}^{-1}$ of enrofloxacin in the second passage were used. Statistical analyses were performed using a one-way analysis of variance, with a $P$ value of $<0.05$ being considered significant.

\section{PCR amplification and sequencing analysis of $\mathrm{gyrA}$}

PCR amplification of the QRDR of gyrA was carried out by using the primers, GYRAF (5'-CGTTGGTGACGTAATCGGTA-3') and GYRAR (5'-CCGTGCCG TCATAGTTATCA- $\left.3^{\prime}\right) .{ }^{29}$ Amplification was performed in a reaction volume of $25 \mu \mathrm{l}$ by using FastStart Taq DNA Polymerase (Roche Applied Science, Indianapolis, IN, USA). Each reaction tube contained $5 \mu \mathrm{l}$ of cell suspension, $2 \mu \mathrm{l}$ of a $10 \mu \mathrm{M}$ primer mixture, $2.5 \mu \mathrm{l}$ of $10 \times \mathrm{PCR}$ reaction buffer with $20 \mathrm{mM} \mathrm{MgCl}_{2}$, $0.5 \mu \mathrm{l}$ of $10 \mathrm{~mm}$ dNTP mix and $0.2 \mu \mathrm{l}$ of $2 \mathrm{U}$ FastStart Taq DNA polymerase. Each 35 cycles consisted of $95^{\circ} \mathrm{C}$ denaturation for $30 \mathrm{~s}, 51^{\circ} \mathrm{C}$ annealing for $30 \mathrm{~s}$ and $72^{\circ} \mathrm{C}$ extension for $1 \mathrm{~min}$. The first denaturation and the last extension steps were extended for 4 and $5 \mathrm{~min}$, respectively. PCR products were purified by a Qiaquick Gel Extraction Kit (Qiagen, Valencia, CA, USA) and directly sequenced with PCR forward and reverse primers. MEGA version 4 software (Tempe, AZ, USA) was employed for mutation analysis of gyrA sequences. ${ }^{30}$

\section{Effects of efflux pump inhibitors on enrofloxacin sensitivity}

To investigate the effects of efflux pump inhibitors on the sensitivity of $E$. coli to enrofloxacin, $4 \mu \mathrm{l}$ reserpine (Aldrich, Milwaukee, WI, USA) or carbonyl cyanide- $m$-chlorophenylhydrazone (CCCP, Sigma, St Louis, MO, USA), dissolved in dimethyl sulfoxide, was added to one set of duplicate wells in the microtiter plates. The final concentrations of reserpine and CCCP were $20 \mu \mathrm{g} \mathrm{ml}^{-1}$ and $10 \mu \mathrm{M}$, respectively. ${ }^{20,31-32}$ The kinetics of growth were monitored in a Synergy MX spectrophotometer.

\section{Microscopic observation}

The effect of various concentrations of enrofloxacin on the morphology of E. coli ATCC 25922 were examined using a phase-contrast microscope (Nikon Eclipse 80i, Nikon, Melville, NY, USA) with an oil-immersion objective (UPlanF1 100/1.3) after overnight growth of cells in the wells of 96-well microtiter plate without and with $0.01,0.02,0.03,0.06$ and $0.1 \mu \mathrm{g} \mathrm{ml}^{-1}$ of enrofloxacin.

\section{Fatty acid analysis}

Cellular lipids from E. coli grown in MHB with and without 2.5\% fecal extract and enrofloxacin were saponified, methylated and extracted using hexane/ methyl tertiary butyl ether as described by Song et al. ${ }^{33}$ Fatty acid methyl esters were analyzed via GC (Agilent series 6890, Agilent, Santa Clara, CA, USA) by using the SHERLOCK Microbial Identification System (MIDI, Newark, DE, USA) and identification was verified by GC-MS with a Thermo Scientific DSQ II (Thermo Scientific, West Palm Beach, FL, USA), equipped with a DB5-MS capillary column $(30 \mathrm{~m} \times 0.25 \mathrm{~mm}$ inner diameter, film thickness $0.25 \mathrm{~mm})$ with helium as the carrier gas.

\section{RESULTS}

\section{Effect of enrofloxacin on bacterial growth}

The kinetics of growth of E. coli ATCC 25922 were compared in various substrates with and without enrofloxacin (Figure 1). The MIC of enrofloxacin for wild-type E. coli ATCC 25922 was verified to be $0.03 \mu \mathrm{g} \mathrm{ml}^{-1}$. In the first passage, in the absence of enrofloxacin, the maximum growth of $E$. coli was similar in all media after $15 \mathrm{~h}$ of incubation (Figure 1a), but its growth rates in different media varied in the first $5 \mathrm{~h}$ (Figure $1 \mathrm{~b})$. In the presence of sub-MIC $\left(0.01 \mu \mathrm{g} \mathrm{ml}^{-1}\right)$ of enrofloxacin, growth of E. coli was substantially higher in the medium supplemented with 1 or $2.5 \%$ sterilized fecal extract than in other media (Figures 1a and c). The medium with sterilized fecal extract (1 and 2.5\%) also allowed the growth of E. coli in the presence of 0.03 and $0.06 \mu \mathrm{g} \mathrm{ml}^{-1}$ enrofloxacin, which are equal to 1 and 2 times the MIC of the drug, respectively, for this strain (Figure 1a).

In the second and third passages, the bacteria that had survived in $0.01 \mu \mathrm{g} \mathrm{ml}^{-1}$ of enrofloxacin (sub-MIC) were used for inoculation. They grew well in all media containing up to the MIC $\left(0.03 \mu \mathrm{g} \mathrm{ml}^{-1}\right)$ of enrofloxacin. Better growth was observed in media supplemented 

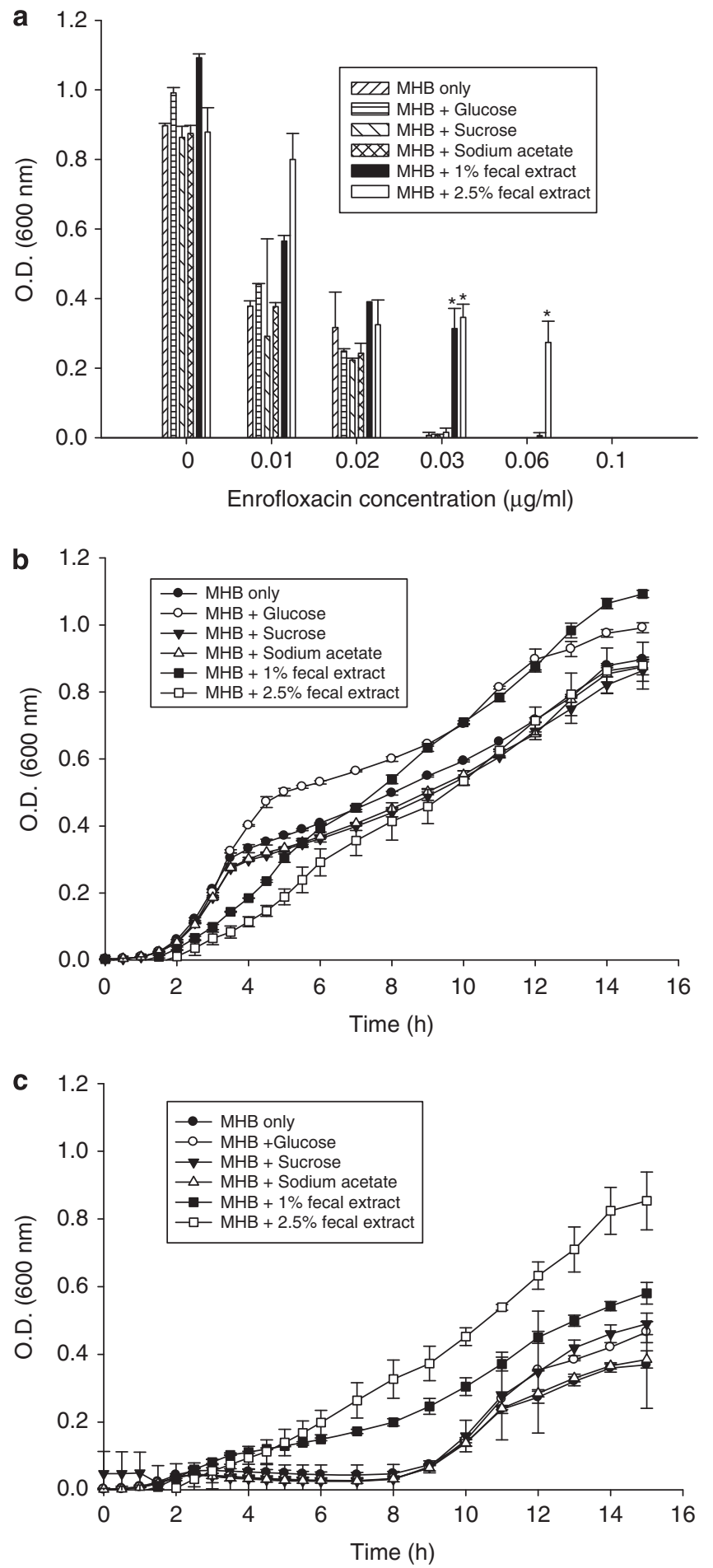

Figure 1 Effects of different concentrations of enrofloxacin on growth of E. coli ATCC 25922 in media containing $5 \mathrm{~mm}$ glucose, sucrose or sodium acetate, or 1 or $2.5 \%$ sterilized extract from a human fecal sample, in the first passage. Symbols represent averages of triplicates from three samples and error bars represent the standard deviations. (a) Maximum growth of $E$. coli $\left(\mathrm{OD}_{600}\right)$ observed in various media with each enrofloxacin concentration. (b) The kinetics of growth of $E$. coli in media with different supplements in the absence (b) and presence (c) of $0.01 \mu \mathrm{g} \mathrm{ml}^{-1}$ enrofloxacin. *Indicates statistically significant differences from control $(P<0.05)$. with sugars and sterilized fecal extracts (Figure 2). Media supplemented with sterilized fecal extracts and sugars also better supported the growth of $E$. coli with 0.06 and $0.1 \mu \mathrm{g} \mathrm{ml}^{-1}$ of enrofloxacin in the second (Figure $2 \mathrm{a}$ ) and third (Figure $2 \mathrm{~b}$ ) passages. Strains showed a slower rate of growth in the first $5 \mathrm{~h}$ of incubation in the media supplemented with sterilized fecal extracts than in others, but then the rate of growth increased substantially in comparison with the rates of growth in other media (Figures $2 \mathrm{c}$ and $\mathrm{d}$ ). This increase in the rate of growth was more pronounced with concentrations of enrofloxacin higher than the MIC $\left(0.03 \mu \mathrm{g} \mathrm{ml}^{-1}\right)$.

Comparison of the sequences of the QRDR of E. coli strains

To find out if the bacteria that survived in higher concentrations of enrofloxacin than the MIC had mutations in the QRDR of gyrA, the QRDR primers were used to amplify $251 \mathrm{bp}$ fragments from the wildtype and the cell mixtures that grew with different concentrations of enrofloxacin in the second and third passages. The PCR amplicons were sequenced and analyzed. The sequences of the QRDR from all of the E. coli strains were identical, regardless of the level of sensitivity to enrofloxacin.

\section{Effects of efflux pump inhibitors on sensitivity of $E$. coli to enrofloxacin}

The effect of efflux pump inhibitors on sensitivity of $E$. coli to $0.1 \mu \mathrm{g} \mathrm{ml}^{-1}$ enrofloxacin was also examined in MHB supplemented with $5 \mathrm{~mm}$ sucrose or $2.5 \%$ sterilized fecal extract in the second and third passages. Reserpine and CCCP increased the sensitivity of bacteria to $0.1 \mu \mathrm{g} \mathrm{ml}^{-1}$ of enrofloxacin in the medium containing sucrose, but their effect was not observed in the medium supplemented with sterilized fecal extract (Figure 3).

\section{Effect of enrofloxacin on cell structure}

Enrofloxacin, even at low concentrations, affected the morphology of E. coli cells. The bacteria exposed to $0.01 \sim 0.1 \mu \mathrm{g} \mathrm{ml}^{-1}$ of enrofloxacin were elongated. The increase in the number of elongated cells varied with the concentration of enrofloxacin (Figure 4).

\section{Effects of sterilized fecal extract on lipid composition}

The major saturated and unsaturated fatty acids were measured in E. coli grown in the medium with and without $2.5 \%$ sterilized fecal extract. In the bacteria grown with $2.5 \%$ sterilized fecal extract, the proportions of the saturated fatty acids, heptadecanoic acid $\left(\mathrm{C}_{17: 0}\right)$ and octadecanoic acid $\left(\mathrm{C}_{18: 0}\right)$ and of the cyclopropane-substituted methylene-heptadecanoic acid $\left(\mathrm{C}_{17: 0}\right.$ cyclo $)$ and cyclopropane-substituted methylene-nonadecanoic acid $\left(\mathrm{C}_{19: 0}\right.$ cyclo $)$ had increased, but the main saturated fatty acid hexadecanoic acid $\left(\mathrm{C}_{16: 0}\right)$ had decreased. The decrease was also observed in the proportion of the two unsaturated fatty acids, $(Z)$-9-hexadecenoic acid $\left(\mathrm{C}_{16: 1} \omega 7 \mathrm{c}\right)$ and $(E)$-11-octadecenoic acid $\left(\mathrm{C}_{18: 1} \omega 7 \mathrm{c}\right)$ (Figure $\left.5 \mathrm{a}\right)$.

In the cells grown with and without enrofloxacin in the absence of fecal extract, the ratios of saturated to unsaturated fatty acids were 1.7 and 2.2, respectively, but in the presence of $2.5 \%$ sterilized fecal extract, the ratios increased to 2.4 and 3.9, respectively (Figure 5b). This increase in the ratio in the presence of fecal extract was the result of increases in the amounts of heptadecanoic acid, octadecanoic acid and cyclopropane fatty acids $\left(\mathrm{C}_{17: 0}\right.$ cyclo, and $\mathrm{C}_{19: 0}$ cyclo $)$, even though the amount of hexadecanoic acid had decreased.

\section{DISCUSSION}

Colonic bacteria are exposed to antibiotics and may develop resistance to them. We used enrofloxacin as a model compound to examine the 

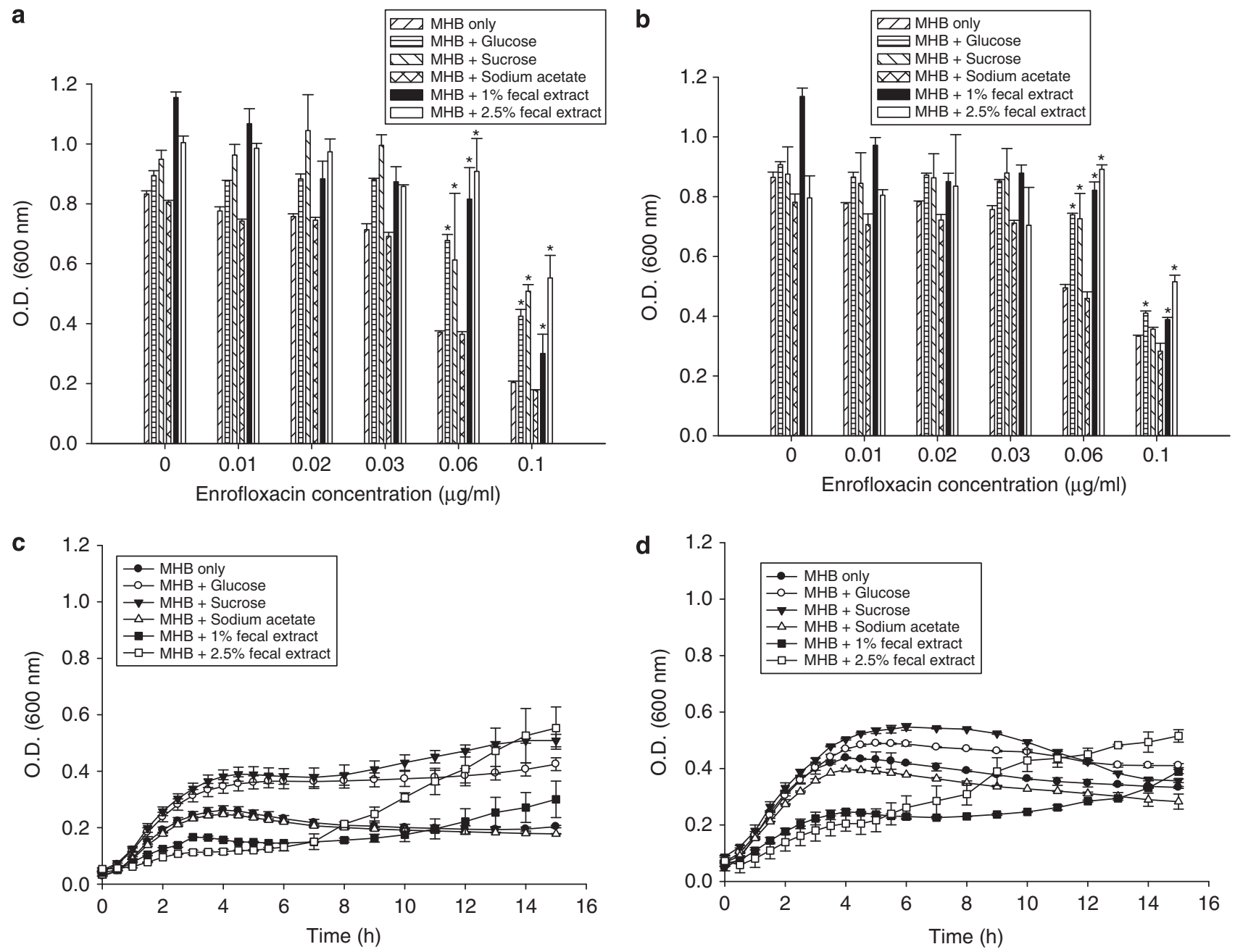

Figure 2 Comparison of the growth $\left(\mathrm{OD}_{600}\right)$ of E. coli ATCC 25922 that had survived a sub-MIC concentration of enrofloxacin $\left(0.01 \mu \mathrm{g} \mathrm{ml} \mathrm{I}^{-1}\right)$, with different concentrations of enrofloxacin $\left(0.01 \sim 0.1 \mu \mathrm{g} \mathrm{ml}^{-1}\right)$ in the second and third passages. The bacteria were incubated for $15 \mathrm{~h}$ in Mueller-Hinton broth containing $5 \mathrm{~mm}$ glucose, sucrose or sodium acetate, or 1 or $2.5 \%$ extract from a human fecal sample. Symbols represent averages of triplicates from three human fecal samples and error bars represent the standard deviations. Maximum cell growth was measured in the second (a) and third (b) passages in media with different supplements. Kinetics of growth of $E$. coli in $0.1 \mu \mathrm{g} \mathrm{ml}^{-1}$ of enrofloxacin were measured in the second (c) and third (d) passages in media with different supplements. ${ }^{*}$ Indicates statistically significant differences from control $(P<0.05)$.

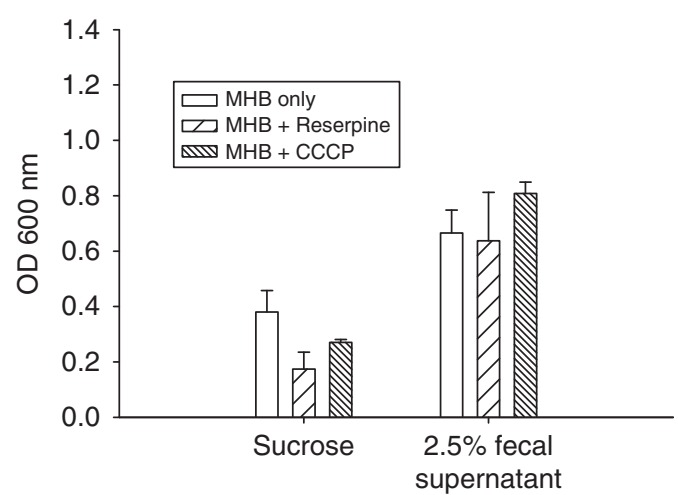

Figure 3 Effects of reserpine and carbonyl cyanide- $m$-chlorophenylhydrazone (CCCP) on the growth of E. coli ATCC 25922 with $0.1 \mu \mathrm{g} \mathrm{ml} \mathrm{l}^{-1}$ enrofloxacin in Mueller-Hinton broth containing sucrose and $2.5 \%$ sterilized human fecal extract in the third passage. Symbols represent averages of triplicates from three samples and error bars represent the standard deviations. effect of low concentrations of a fluoroquinolone on the resistance development in E. coli in the presence of fecal extract. We found that at low concentration $(2.5 \%)$ of sterilized fecal extract, the growth of E. coli was enhanced in MIC and sub-MIC levels of enrofloxacin in the first passage. The strain grew in 2-3 times the MIC of enrofloxacin in the second and third passages without developing mutations in the QRDR region of gyrA. Efflux pump inhibitors increased the sensitivity of the resistant strain to enrofloxacin, but had less effect on increasing sensitivity of the cells in the presence of sterilized fecal extract. The fecal extract had affected the lipid composition of the bacterial membrane in the resistant strain.

Decreased sensitivity of $E$. coli in sterilized fecal extract in the first passage may indicate either decreased potency of antibiotics or reduced cell penetration. Kamberi et al. ${ }^{34}$ reported that at lower $\mathrm{pH}$ (for example, in urine) the piperazine-containing fluoroquinolones, such as enrofloxacin, are positively charged, which may decrease their penetration into bacteria and thus decrease their activity. Fecal $\mathrm{pH}$ generally is 6.4 , but ranges from 5.4 to 7.8 among healthy adults ${ }^{35}$ 


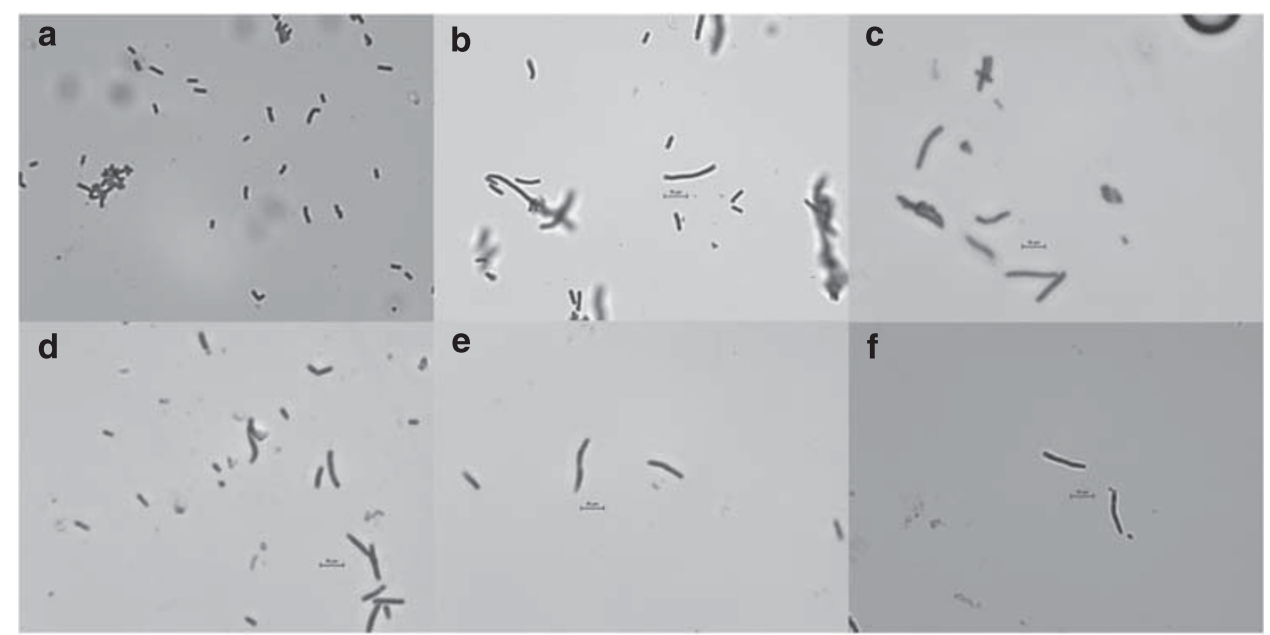

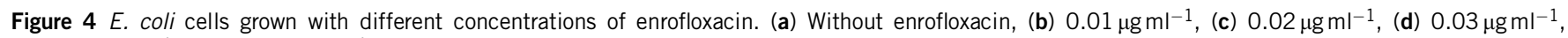
(e) $0.06 \mu \mathrm{g} \mathrm{ml}^{-1}$ and (f) $0.1 \mu \mathrm{g} \mathrm{ml} \mathrm{l}^{-1}$. A full color version of this figure is available at The Journal of Antibiotics journal online.

a
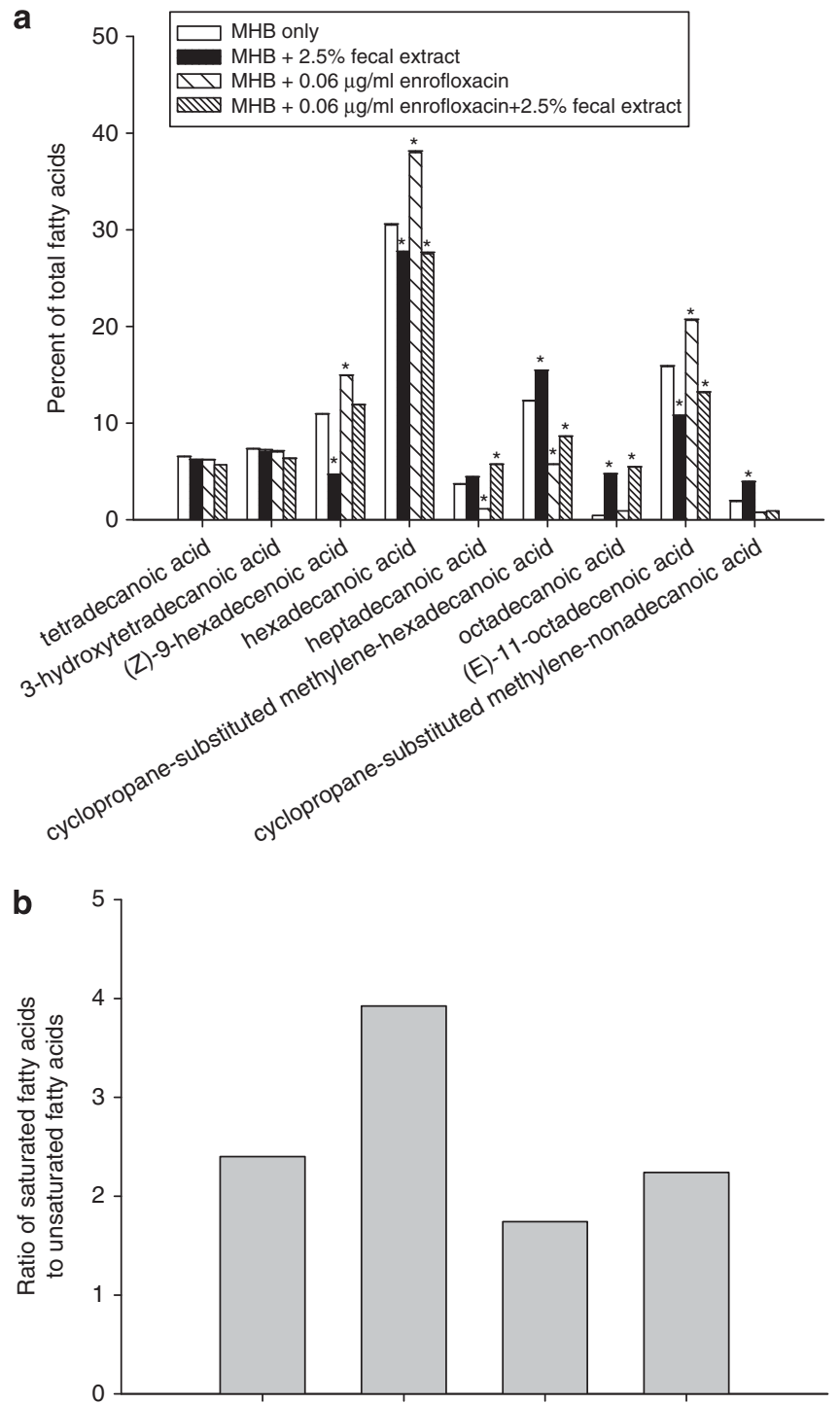

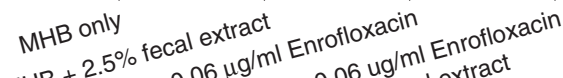

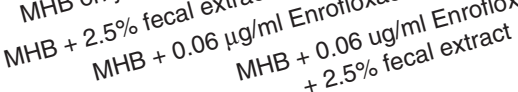

Figure 5 Fatty acid composition of lipids of $E$. coli grown with and without $0.06 \mathrm{\mu g} \mathrm{ml}^{-1}$ enrofloxacin in Mueller-Hinton broth with and without $2.5 \%$ fecal extract (a). Symbols represent averages of triplicates from one human fecal sample and error bars represent the standard deviations. Ratio of saturated to unsaturated fatty acids (b). *Indicates statistically significant differences from control $(P<0.05)$.

and is important in determining binding of ionizable drugs. In our study, the average fecal $\mathrm{pH}$ was 6.3 and the $\mathrm{pH}$ of media supplemented with the sterilized fecal extract was the same as the $\mathrm{pH}$ of other media, indicating that decrease in sensitivity to enrofloxacin in the presence of sterilized fecal extract was not related to change in $\mathrm{pH}$. HPLC analysis showed that fecal extract did not change the structure of enrofloxacin (data not shown). The recovery rate was more than $90 \%$, indicating that it was not eliminated by binding to the fecal extract. However, we can not preclude unknown conformational changes that may have occurred, either in the cells or in the drug that may have affected interaction of the drug with the cells or the drug penetration into the cell. Interaction of fluoroquinolones with organic matter has been shown. ${ }^{36,37}$

The effect of sterilized fecal extract was more pronounced in the second and third passages, in which the E. coli cells were able to grow in the medium with $\geqslant 3 \times \mathrm{MIC}$. Also, the cells grown with enrofloxacin were elongated (Figure 4), which was similar to previously reported observations. ${ }^{38}$ The cells were not elongated in the medium without enrofloxacin. Bacteria growing in higher concentrations of enrofloxacin $\left(0.1 \mu \mathrm{g} \mathrm{ml}^{-1}\right)$ had more elongated cells and did not have mutations in $g y r A$, which has been shown to be the reason for decreased sensitivity of E. coli, including those exposed to low concentrations of fluoroquinolones. ${ }^{39}$ Both inhibitors of the efflux pump, reserpine and CCCP, inhibited the growth of $E$. coli in the presence of enrofloxacin (data not shown), as has been shown previously for other fluoroquinolones. ${ }^{32}$ However, in the media containing sterilized fecal extracts, no increase in sensitivity to enrofloxacin was observed in the presence of these pump inhibitors. It could be hypothesized that fecal extract may have decreased the permeability of the cells to enrofloxacin, either by affecting the membrane or by binding to the drug, similar to those reported for other organic matter. ${ }^{36,37}$ We observed that $2.5 \%$ sterilized fecal extract affected the ratio of saturated to unsaturated fatty acids in E. coli. Cells grown with $2.5 \%$ sterilized fecal extract had a higher ratio of saturated to unsaturated fatty acids than that in the 
control cells grown with and without enrofloxacin. Changes in relative proportions of saturated and unsaturated fatty acids affect the fluidity and permeability of the cell membrane, its physical state and functions under various conditions. ${ }^{40-42}$ The alteration in the fatty acid composition caused by sterilized fecal extract may have affected not only bacterial membrane functions but also the sensitivity of bacteria to antimicrobial agents, possibly by influencing its entry into the cell.

The CLSI breakpoint for enrofloxacin is $1 \mu \mathrm{g} \mathrm{ml}^{-1}$ for E. coli. ${ }^{34}$ The rapid threefold increase in the MIC of enrofloxacin for E. coli, after only one passage at a sub-MIC concentration in sterilized fecal extract, may indicate potential for rapid growth of this bacterium in the presence of enrofloxacin under colonic conditions. Catry et al., ${ }^{43}$ evaluating resistance of $E$. coli through the digestive tract of calves (duodenum, jejunum, cecum, colon and rectum), found the highest percentage of enrofloxacin-resistant $E$. coli in the colon.

In conclusion, exposure to sub-inhibitory concentrations of enrofloxacin in media supplemented with sterilized human fecal extract reduced sensitivity of a strain of $E$. coli to a concentration of enrofloxacin three times higher than the MIC. The sterilized fecal extract altered the proportion of unsaturated and saturated fatty acids in $E$. coli, which may have affected the transport of enrofloxacin into the cells. This is the first study in which the influence of fecal extract on bacterial sensitivity to a drug has been investigated. The exact component(s) of the fecal extract that has affected the E. coli sensitivity to enrofloxacin is not known and merits investigation.

\section{ACKNOWLEDGEMENTS}

We thank Donald Paine for providing bacterial strains, Hyeri Ahn, Monica Yun and Inhae Sung for technical assistance, and Dr John B Sutherland and Dr Bruce D Erickson for reviewing the manuscript. The views presented in this article do not necessarily reflect those of the Food and Drug Administration.

1 Cerniglia, C. E. \& Kotarski, S. Evaluation of veterinary drug residues in food for their potential to affect human intestinal microflora. Regul. Toxicol. Pharmacol. 29, 238-261 (1999).

2 Cerniglia, C. E. \& Kotarski, S. Approaches in the safety evaluations of veterinary antimicrobial agents in food to determine the effects on the human intestinal microflora. J. Vet. Pharmacol. Ther. 28, 3-20 (2005).

3 Cho, H. J. et al. Monitoring of fluoroquinolone residual levels in chicken eggs by microbiological assay and confirmation by liquid chromatography. Biomed. Chromatogr. 22, 92-99 (2008).

4 Reyes-Herrera, I. \& Donoghue, D. J. Antibiotic residues distribute uniformly in broiler chicken breast muscle tissue. J. Food Prot. 71, 223-5 (2008).

5 Donoghue, D. J., Reyes-Herrera, I., Schneider, M. J. \& Blore, P. J. The relationship between blood and muscle samples to monitor for residues of the antibiotic enrofloxacin in chickens. Poult. Sci. 90, 481-485 (2011)

6 Angulo, F. J., Nargund, V. N. \& Chiller, T. C. Evidence of an association between use of anti-microbial agents in food animals and anti-microbial resistance among bacteria isolated from humans and the human health consequences of such resistance. J. Vet. Med. Series B-Infect. Dis. Vet. Public Health 51, 374-379 (2004).

7 Carman, R. J. et al. Antibiotics in the human food chain: Establishing no effect levels of tetracycline, neomycin, and erythromycin using a chemostat model of the human colonic microflora. Regul. Toxicol. Pharmacol. 43, 168-180 (2005).

8 Perrin-Guyomard, A. et al. Impact of ciprofloxacin in the human-flora-associated (HFA) rat model: Comparison with the HFA mouse model. Regul. Toxicol. Pharmacol. 45, 66-78 (2006)

9 Silley, P. Impact of antimicrobial residues on gut communities: are the new regulations effective? J. Appl. Microbiol. 102, 1220-1226 (2007)

10 Finlay, B. B. et al. Antibiotic treatment alters the colonic mucus layer and predisposes the host to exacerbated Citrobacter rodentium-induced colitis. Infect. Immun. 79, 1536-1545 (2011).

11 EMA. The European Agency for the Evaluation of Medicinal products. Enrofloxacin (modification for bovine, porcine and poultry). EMEA/MRL/388/98-Final. Available at: 〈www.ema.europa.eu/pdfs/vet/mrls/038898en.pdf 〉 (1998).

12 Joint FAO/WHO Expert Committee on Food Additives (JECFA). Evaluation of Certain Veterinary Drug Residues in Food: Forty-eight Meeting of the Joint FAO/WHO Expert Committee on Food Additives. WHO technical Report Series No. 39.: Geneva, Switzerland (1997).
13 Willmott, C. J. R. \& Maxwell, A. A single point mutation in the DNA gyrase-a protein greatly reduces binding of fluoroquinolones to the gyrase-DNA complex. Antimicrob. Agents Chemother. 37, 126-127 (1993).

14 Vila, J. et al. Association between double mutation in gyrA gene of ciprofloxacinresistant clinical isolates of Escherichiacoli and MICs. Antimicrob. Agents Chemother. 38, 2477-2479 (1994).

15 Ouabdesselam, S., Hooper, D. C., Tankovic, J. \& Soussy, C. J. Detection of gyrA and gyrB mutations in quinolone-resistant clinical isolates of Escherichiacoli by singlestrand conformational polymorphism analysis and determination of levels of resistance conferred by 2 different single gyrA mutations. Antimicrob. Agents Chemother. 39, 1667-1670 (1995)

16 Everett, M. J., Jin, Y. F., Ricci, V. \& Piddock, L. J. V. Contributions of individual mechanisms to fluoroquinolone resistance in 36 Escherichia coli strains isolated from humans and animals. Antimicrob. Agents Chemother. 40, 2380-2386 (1996).

17 Miyamae, S., Nikaido, H., Tanaka, Y. \& Yoshimura, F. Active efflux of norfloxacin by Bacteroides fragilis. Antimicrob. Agents Chemother. 42, 2119-2121 (1998).

18 Oethinger, M., Kern, W. V., Jellen-Ritter, A. S., McMurry, L. M. \& Levy, S. B. Ineffectiveness of topoisomerase mutations in mediating clinically significant fluoroquinolone resistance in Escherichia coli in the absence of the AcrAB efflux pump. Antimicrob. Agents Chemother. 44, 10-13 (2000).

19 Piddock, L. J. V., White, D. G., Gensberg, K., Pumbwe, L. \& Griggs, D. J. Evidence for an efflux pump mediating multiple antibiotic resistance in Salmonella enterica serovar Typhimurium. Antimicrob. Agents Chemother. 44, 3118-3121 (2000).

20 Coldham, N. G., Webber, M., Woodward, M. J. \& Piddock, L. J. V. A 96-well plate fluorescence assay for assessment of cellular permeability and active efflux in Salmonella enterica serovar Typhimurium and Escherichia coli. J. Antimicrob. Chemother. 65, 1655-1663 (2010).

21 Stephen, A. M. \& Cummings, J. H. The microbial contribution to human faecal mass. J. Med. Microbiol. 13, 45-56 (1980).

22 Wagman, G. H., Bailey, J. V. \& Weinstein, M. J. Binding of aminoglycosides to feces. Antimicrob. Agents Chemother. 6, 415-7 (1974).

23 Hazenberg, M. P., Pennock-Schroder, A. M., Van den Boom, M. \& Van de Merwe, J. P. Binding to and antibacterial effect of ampicillin, neomycin and polymyxin B on human feces. J. Hyg. Camb 93, 27-34 (1984).

24 Veringa, E. M. \& van der Waaij, D. Biological inactivation by feces of antimicrobial drugs applicable in selective decontamination of the digestive tract. J. Antimicrob. Chemother. 14, 605-612 (1984).

25 De Vries-Hospers, H., Jansen, G., Tonk, R., Oenema, D. \& van der Waaij, D. The in vitro inactivation of thirteen beta-lactam antibiotics by other mechanisms than adsorption to faecal substance. Infection 21, 127-130 (1993).

26 Van Saene, J. J. M., van Saene, H. K. F. \& Lerk, C. F. Inactivation of quinolones. $J$ Infect. Dis 153, 999-1000 (1986).

27 Costons, G.M.P.J., Bos, L. P., Engels, L.G.J.B. \& Janson, P. C. W. A new method for chemical analysis of faeces. Clinica Chimica Acta 150, 197-203 (1985).

28 Pasquali, F. \& Manfreda, G. Mutant prevention concentration of ciprofloxacin and enrofloxacin against Escherichia coli, Salmonella typhimurium and Pseudomonas aeruginosa. Vet. Microbiol. 119, 304-310 (2007).

29 Eaves, D. J., Liebana, E., Woodward, M. J. \& Piddock, L. J. V. Detection of gyrA mutations in quinolone-resistant Salmonella enterica by denaturing high-performance liquid chromatography. J. Clin. Microbiol. 40, 4121-4125 (2002).

30 Tamura, K., Dudley, J., Nei, M. \& Kumar, S. MEGA4: Molecular evolutionary genetics analysis (MEGA) software version 4.0. Mol. Biol.Evol. 24, 1596-1599 (2007).

31 Chapman, J. S. \& Georgopapadakou, N. H. Fluorometric assay for fleroxacin uptake by bacterial-cells. Antimicrob. Agents Chemother. 33, 27-29 (1989).

32 Rafii, F., Park, M. \& Wynne, R. Evidence for active drug efflux in fluoroquinolone resistance in Clostridium hathewayi. Chemotherapy 51, 256-262 (2005).

33 Song, B., Palleroni, N. J., Kerkhof, L. J. \& Häggblom, M. M. Characterization of halobenzoate-degrading, denitrifying Azoarcus and Thauera isolates and description of Thauera chlorobenzoica sp. nov. Int. J. Syst. Evol. Microbiol. 51, 589-602 (2001).

34 Kamberi, M. et al. Influences of urinary $\mathrm{pH}$ on ciprofloxacin pharmacokinetics in humans and antimicrobial activity in vitro versus those of sparfloxacin. Antimicrob. Agents Chemother. 43, 525-529 (1999).

35 Costongs, G.M.P.J., Bos, L. P., Engels, L.G.J.B. \& Janson, P. C. W. A new method for chemical-analysis of feces. Clin. Chim. Acta 150, 197-203 (1985).

36 Aristilde, L. \& Sposito, G. Binding of ciprofloxacin by humic substances: A molecular dynamics study. Environ. Toxicol. Chem. 29, 90-98 (2010).

37 Hao, W- L. \& Lee, Y- K. Microflora of the gastrointestinal tract: A review. Methods Mol. Biol. 268, 491-502 (2004).

38 Cook, T. M., Brown, K. G., Boyle, J. V. \& Goss, W. A. Bactericidal action of nalidixic acid on Bacillus subtilis. J. Bacteriol. 92, 1510-1514 (1966).

$39 \mathrm{Li}, \mathrm{Q}$. X., Bi, X. M., Diao, Y. J. \& Deng, X. M. Mutant-prevention concentrations of enrofloxacin for Escherichia coli isolates from chickens. Am. J. Vet. Res. 68, 812-815 (2007).

40 Sinensky, M. Homeoviscous adaptation-a homeostatic process that regulates the viscosity of membrane lipids in. Escherichia coli. Proc. Natl Acad. Sci. USA 71, 522-525 (1974).

41 Russell, N. J. \& Fukunaga, N. A comparison of thermal adaptation of membrane lipids in psychrophilic and thermophilic bacteria. FEMS Microbiol. Rev. 75, 171-182 (1990).

42 Mejỳa, R., Gomez-Eichelmann, M. C. \& Fernandez, M. S. Membrane fluidity of Escherichia coli during heat-shock. Biochem. Biophys. Acta 1239, 195-200 (1995).

43 Catry, B. et al. Antimicrobial resistance patterns of Escherichia coli through the digestive tract of veal calves. Microb. Drug Resist. -Mechanisms Epidemiol. Disease 13, 147-150 (2007) 